\title{
Alcohol consumption in arthritic patients: clinical and laboratory studies
}

\author{
ANTHONY BRADLOW AND ALASTAIR G MOWAT \\ From the Rheumatology Unit, Nuffield Orthopaedic Centre, Headington, Oxford OX3 $7 L D$
}

SUMMARY In popular belief patients with chronic arthritis take alcohol for its analgesic effect. To test this we studied by validated questionnaire the past and present alcohol consumption of 103 patients with primary osteoarthritis of the hip (OA), 95 patients with rheumatoid arthritis (RA), and 90 orthopaedic non-arthritic controls. OA men were most likely and RA men least likely to have been heavy drinkers at any time of their lives. Mean red corpuscular volume (MCV), $\gamma$-glutamyltransferase (GGT), and serum uric acid (SUA) levels did not correlate with reported alcohol consumption. Two of $93 \mathrm{OA}$ femoral heads examined had avascular change; both were from heavy drinkers. The abstemiousness of RA men compared with their OA counterparts was due to a striking increase in joint pain after drinking alcohol $(p=0 \cdot 004)$, fear of adverse drug reactions with alcohol, and a widespread belief not expressed by $\mathrm{OA}$ men that 'alcohol and arthritis do not mix'.

Key words: rheumatoid arthritis, osteoarthritis, osteonecrosis, alcohol drinking.

Alcohol consumption has almost doubled in the United Kingdom over the past twenty years. ${ }^{1}$ A growing national awareness of alcohol-related problems has followed, ${ }^{23}$ but there are few studies of alcohol consumption in specific hospital inpatient groups. ${ }^{4-6} 20 \%$ to $27 \%$ of inpatients, ${ }^{56}$ and $32 \%$ of casualty department attenders ${ }^{7}$ in Britain have been found to have medical or social problems related to drinking. Patterns of alcohol consumption in chronic arthritics before and after the development of arthritis are not known. Knowledge of these patterns would add to the psychological profile of arthritic patients ${ }^{8}$ and would extend the information on the drinking habits of a major group of patients with chronic disease. ${ }^{9}$

Excessive alcohol consumption has been causally linked with gout, ${ }^{10}$ pancreatitis-associated arthritis, ${ }^{12}$ and 'spontaneous' avascular necrosis of the femoral head (SANFH). ${ }^{13-16}$ The latter link remains unproved but strongly suspected because SANFH is reported most frequently from countries with a high alcohol consumption per person, such as the USA $^{17}$ and France. ${ }^{18}$ However, its true frequency may be greater, since by the time patients

Accepted for publication 13 September 1984.

Correspondence to Dr A Bradlow. seek medical attention there may be advanced femoral head destruction with secondary osteoarthritis radiologically indistinguishable from other causes of femoral head damage. ${ }^{19-21}$

We have compared lifetime alcohol consumption in patients with rheumatoid arthritis (RA), in patients with severe symptomatic hip degeneration (OA), and in controls without symptomatic arthritis. Further, we attempted to confirm reports that mean red corpuscular volume (MCV), serum $\gamma$ glutamyltransferase (GGT), and serum uric acid (SUA) can be correlated with admitted alcohol consumption. ${ }^{22} 23$

\section{Patients and methods}

We studied unselected patients over the age of 40 admitted under five consultants to the Nuffield Orthopaedic Centre in the 16-month period from September 1981 to February 1983. The OA group comprised 103 patients (52 male) admitted for total hip replacement for 'primary' degenerative hip disease. Those with hip degeneration secondary to well-documented past or present disease such as congenital hip dislocation, femoral neck fractures, inflammatory polyarthritis, and Perthes' disease 
were excluded. The RA group comprised 95 patients ( 48 male) with definite or classical rheumatoid arthritis $^{24}$ admitted to the rheumatology unit for both medical and surgical therapy. The control group comprised 90 patients ( 46 male) admitted for minor orthopaedic surgery, usually on hands or feet, who did not fit into the OA or RA groups. In an attempt to define the control group more clearly patients with Dupuytren's contracture, which is claimed to be alcohol related ${ }^{25}$ symptomatic arthritis of large weight-bearing joints, inflammatory joint disease, or painful conditions causing chronic disability (such as low backache) were excluded from this group. Any patient unwilling or unable to answer the questionnaire was excluded from the study.

\section{QUESTIONNAIRE}

Each patient answered a structured questionnaire which was completed by an interviewer $(A B)$ who was aware of the patient's diagnosis. The questionnaire was based on the QF categorisation of Griffiths Edwards. ${ }^{26}$ Details of day by day alcohol consumption during a 'typical' recent week were recorded and used as a basis for comparison with weekly consumption 1,10 , and 20 to 30 years previously with life events such as marriage and military service as 'anchor points' to help recollection ('time-line follow-back method'). ${ }^{27}$ Drinking before the age of 30 was disregarded because we felt it would be unrepresentative of patterns in future years. Weekly consumption was scored 1-9 (Table 1) and the scores awarded were used for comparisons at the end of the study.

In addition to establishing alcohol consumption the questionnaire sought information about whether

Table 1 Alcohol consumption scores: QF categorisation*

\begin{tabular}{|c|c|}
\hline $\begin{array}{l}\text { 1. Nil or occasional } \\
\text { 2. Infrequent light } \\
\text { 3. Frequent light }\end{array}$ & $\begin{array}{l}\text { Less than } 1 \text { drink per month } \\
\text { Less than } 4 \text { drinks per month } \\
\text { Less than } 4 \text { drinks per week } \\
\text { Drinking on } 2 \text { or fewer days every } \\
\text { week }\end{array}$ \\
\hline 4. Steady & $\begin{array}{l}5 \text { to } 21 \text { drinks per week } \\
\text { Drinking on } 3 \text { to } 5 \text { days per week }\end{array}$ \\
\hline 5. Steady & $\begin{array}{l}\text { As (4) but admits to drinking } \\
7 \text { days per week }\end{array}$ \\
\hline 6. Threshold & $\begin{array}{l}28 \text { to } 56 \text { drinks per week } \\
\text { Drinking on } 4 \text { or fewer days weekly }\end{array}$ \\
\hline 7. $\mathrm{He}$ & $\begin{array}{l}28 \text { to } 56 \text { drinks per week } \\
\text { Daily consumption }\end{array}$ \\
\hline $\begin{array}{l}\text { 8. Very heavy } \\
\text { 9. Gross }\end{array}$ & $\begin{array}{l}60 \text { to } 100 \text { drinks per week } \\
\text { More than } 100 \text { drinks per week }\end{array}$ \\
\hline
\end{tabular}

'Drink' $=1 / 2$ pint $(0.31)$ beer or lager $=$ standard measure of spirits $=$ glass of wine or sherry (small measure) $=8-10 \mathrm{~g}$ alcohol.

${ }^{*}$ Modified from reference 26.

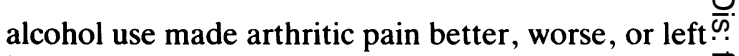
it unchanged. Patients were also asked whether the $\overrightarrow{\vec{s}}$ development of arthritis had affected the frequency with which they went out to consume alcohol at $\frac{C}{0}$ public houses or clubs.

Seventeen patients were retested by the same $\frac{\widetilde{\pi}}{\widetilde{\alpha}}$ interviewer at intervals of 2 weeks to 6 months after the original questionnaire. Seven of these patients कs were also requestioned by other interviewers. In all $\overrightarrow{0}$ cases the coefficient of correlation (r) between scores was 0.88 or better $(\mathrm{p}<0.001)$; however, $\vec{\omega}$ questions concerning consumption 20 or 30 years previously were less well validated $(r=0.6, p<0.05)$.

BIOCHEMICAL AND HAEMATOLOGICAL INDICES OF ALCOHOL CONSUMPTION

MCV, SUA, and serum GGT were measured in all patients on admission to hospital. Venesection was performed between 9 and 10 am without preced- $\vec{r}$ ing restriction of food or fluid intake. SUA was measured by the uricase method and GGT was 음 measured at a later date on a batch of sera $\vec{A}$ stored at $-15^{\circ} \mathrm{C}$ by a modification of the method of ${ }_{\infty}^{\circ}$ Orlowski and Meister. ${ }^{28} \mathrm{MCV}$ was measured by ${ }^{\mathrm{c}}$ automated counter (Coulter Model S Plus).

\section{HISTOLOGY}

Examination of resected femoral heads for avascularo necrosis was performed in 93 of the 103 OAD

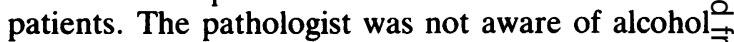
scores in any patients but was aware of our interesto in the presence or absence of avascular necrosis in the resected femoral heads.

\section{STATISTICS}

Correlation between alcohol score, SUA, MCV, and GGT was assessed by linear regression analysis. In other comparisons unpaired $t$ tests and the Mann-Whitney $U$ test were used for continuous variables. The $\chi^{2}$ test with Yates's correction and Fisher's exact test were used for discrete variables. Product-moment correlation coefficients were used where relevant.

\section{Results}

Two hundred and ninety patients were approached to take part in the study. Only two refused. Age ando disease duration in the different patient groups areo detailed in Table 2. Among the men the controls were significantly younger than $O A$ patients.? $(p<0.05)$, while RA disease duration was signifi- $D$ cantly longer than that of $O A(p<0 \cdot 01)$. Female $O A \stackrel{P}{O}$ patients were significantly older than both $\mathrm{RA}_{\stackrel{\mathrm{D}}{\mathrm{D}}}$ patients $(p<0.02)$ and controls $(p<0 \cdot 03)$. Disease ${ }^{\circ}$ duration was not significantly longer in femaleo patients with RA than in those with OA. 
Table 2 Patient characteristics

\begin{tabular}{|c|c|c|c|c|}
\hline & \multicolumn{2}{|c|}{ Age (years) } & \multicolumn{2}{|c|}{$\begin{array}{l}\text { Disease duration } \\
\text { (years) }\end{array}$} \\
\hline & Mean & $S D$ & Mean & $S D$ \\
\hline OA men $(n=52)$ & $63 \cdot 6$ & $9 \cdot 7$ & $8 \cdot 1$ & $7 \cdot 1$ \\
\hline RA men $(n=48)$ & $62 \cdot 2$ & $9 \cdot 4$ & $11 \cdot 5$ & $7 \cdot 1 \S$ \\
\hline Control $(n=44)$ & $59 \cdot 8$ & $8 \cdot 4^{*}$ & & \\
\hline OA women $(n=51)$ & $68 \cdot 2$ & $7 \cdot 7+$ & $8 \cdot 3$ & $10 \cdot 8$ \\
\hline RA women $(n=47)$ & $63 \cdot 4$ & $9 \cdot 3$ & $12 \cdot 4$ & $10 \cdot 5$ \\
\hline Control $(n=44)$ & $64 \cdot 3$ & $9 \cdot 2 \ddagger$ & & \\
\hline
\end{tabular}

* $p<0.05$ compared with OA men.

$+\mathrm{p}<0.02$ compared with RA women.

$\ddagger \mathrm{p}<0.03$ compared with OA women.

$\S p<0.01$ compared with OA men.

Two controls did not have their age recorded.

Drinking patterns are detailed in Tables 3 and 4. Maximal lifetime consumption is defined as the maximum weekly consumption score for more than 5 years of a patient's life over the age of 30 , i.e., the highest sustained drinking score in a patient's adult life. OA men are overrepresented in the top-scoring groups 7 to 9 , but at current consumption scores the difference is significant only compared with the control group and at maximal lifetime scores with the RA group. Similar numbers of $\mathrm{OA}$ and RA patients had increased alcohol consumption after the development of arthritis and claimed relief of arthritic pain from alcohol. A striking difference was that eight RA men curtailed consumption because their joints were worse even after small amounts of alcohol, whereas no OA men had done so $(p=0 \cdot 004)$. Another three RA men claimed to have
Table 3 Male drinking patterns: top three score groups (7-9) only

\begin{tabular}{lccc}
\hline & $O A$ & $R A$ & Control \\
\hline $\mathrm{n}$ & 52 & 48 & 46 \\
Max 7-9 & 21 & $9^{*}$ & 13 \\
Current 7-9 & 9 & 2 & $1^{*}$ \\
Increase since joint disease & 4 & 6 & \\
Alcohol relieves arthritic pain & 6 & 8 & \\
Alcohol worsens arthritic pain & 0 & $8(+3$ abstained $)$ \\
\hline
\end{tabular}

${ }^{*} \mathrm{p}<0.05$ compared with OA men.

Table 4 Female drinking patterns: score groups 5-9 only

\begin{tabular}{lrrr}
\hline & $O A$ & $R A$ & Control \\
\hline n & 51 & 47 & 44 \\
Max 5-9 & 8 & 11 & 10 \\
$\begin{array}{l}\text { Current 5-9 } \\
\begin{array}{c}\text { Increase since } \\
\text { joint disease }\end{array}\end{array}$ & 5 & 6 & 6 \\
$\begin{array}{c}\text { Alcohol relieves } \\
\quad \begin{array}{l}\text { arthritic pain } \\
\text { Alcohol worsens } \\
\text { arthritic pain }\end{array}\end{array}$ & 2 & 9 & \\
\hline
\end{tabular}

cut alcohol consumption completely as a direct result of arthritis or its treatment. There were no significant differences between drinking patterns in the female groups, though three RA women felt worsening of joint pain after alcohol compared with only one OA woman. The low admitted consumption among women made comparisons difficult and caused us to choose a lower threshold score of five when defining the 'top-scoring' group.

Table 5 Comparison of heaviest and lightest drinkers (significant comparisons only)

\begin{tabular}{|c|c|c|c|}
\hline \multicolumn{4}{|c|}{ Age-OA men (years) } \\
\hline \multicolumn{4}{|c|}{ Maximal lifetime consumption } \\
\hline Score (7-9) & $\mathrm{n}=21$ & Mean 58.3 (SD 8.7) & \multirow[b]{2}{*}{$\mathrm{p}<0.001 t$ test } \\
\hline Score (1-3) & $n=13$ & Mean 69.8 (SD 7.4) & \\
\hline \multicolumn{4}{|c|}{ Current consumption } \\
\hline Score (7-9) & $n=9$ & Mean $57 \cdot 2$ (SD 9) & \multirow[b]{2}{*}{$\mathrm{p}<0.01 \quad t$ test } \\
\hline Score (1-3) & $\mathrm{n}=28$ & Mean 66.8 (SD 8.8 ) & \\
\hline \multicolumn{4}{|c|}{$G G T-R A$ women $(\mathrm{IU} / \mathrm{l})$} \\
\hline Maximal lifetim & consumption & & \multirow[b]{3}{*}{$\mathrm{p}<0.01 t$ test } \\
\hline Score (5-9) & $\mathrm{n}=9$ & Mean $18 \cdot 0$ (SD 9) & \\
\hline Score $(1-2)$ & $n=18$ & Mean $37 \cdot 3$ (SD 25) & \\
\hline \multicolumn{4}{|c|}{$M C V-R A$ women $(\mathrm{fl})$} \\
\hline \multicolumn{4}{|c|}{ Current consumption } \\
\hline Score (5-9) & $n=6$ & Mean 88.5 (SD 7.6) & \multirow[b]{2}{*}{$\mathrm{p}<0.05 t$ test } \\
\hline Score $(1-2)$ & $n=26$ & Mean 81.9 (SD 6.9) & \\
\hline
\end{tabular}


Table 6 Mean values of SUA, MCV and GGT in patients and controls with regression values for correlations of these $\frac{\frac{5}{\omega}}{\text {. }}$ variables with alcohol consumption scores

\begin{tabular}{|c|c|c|c|}
\hline Men & $O A$ & $R A$ & Control \\
\hline $\begin{array}{l}\text { SUA } \\
(\mu \mathrm{mol} / 1 \text { mean } \pm \mathrm{SE})\end{array}$ & $\begin{array}{l}371( \pm 12 \cdot 8) \\
\mathrm{r}=0 \cdot 107\end{array}$ & $\begin{array}{l}335( \pm 21 \cdot 7) \\
r=0 \cdot 274\end{array}$ & $\begin{array}{l}368 \cdot 1( \pm 14 \cdot 5) \\
\mathrm{r}=0 \cdot 219\end{array}$ \\
\hline $\begin{array}{l}\mathrm{MCV} \\
\quad(\mathrm{fl} \text { mean } \pm \mathrm{SE})\end{array}$ & $\begin{array}{l}88 \cdot 3( \pm 0 \cdot 64) \\
r=0 \cdot 153\end{array}$ & $\begin{array}{l}84 \cdot 1( \pm 1 \cdot 15)^{*} \\
r=0 \cdot 137\end{array}$ & $\begin{array}{l}88 \cdot 5( \pm 0 \cdot 96) \\
r=0.082\end{array}$ \\
\hline $\begin{array}{l}\text { GGT } \\
(\text { IU/l mean } \pm \text { SE) }\end{array}$ & $\begin{array}{l}35 \cdot 5( \pm 4 \cdot 5) \\
r=0 \cdot 021\end{array}$ & $\begin{array}{l}56.9( \pm 10.9) \dagger \\
r=0.056\end{array}$ & $\begin{array}{l}28 \cdot 3( \pm 3 \cdot 3) \\
r=0 \cdot 233\end{array}$ \\
\hline $\begin{array}{l}\text { Women } \\
\text { SUA } \\
\quad(\mu \text { mol/ } / \text { mean } \pm \mathrm{SE})\end{array}$ & $\begin{array}{l}303( \pm 12 \cdot 5) \\
\mathrm{r}=0 \cdot 253\end{array}$ & $\begin{array}{l}313( \pm 21 \cdot 4) \\
r=0.006\end{array}$ & $\begin{array}{l}305( \pm 13.7) \\
r=0.068\end{array}$ \\
\hline $\begin{array}{l}\mathrm{MCV} \\
\quad(\mathrm{fl} \text { mean } \pm \mathrm{SE})\end{array}$ & $\begin{array}{l}88 \cdot 8( \pm 0 \cdot 58) \\
r=0 \cdot 243\end{array}$ & $\begin{array}{l}82 \cdot 7( \pm 1 \cdot 04) \ddagger \\
r=0 \cdot 256\end{array}$ & $\begin{array}{l}88.3( \pm 0.56) \\
r=0.05\end{array}$ \\
\hline $\begin{array}{l}\mathrm{GGT} \\
(\mathrm{IU} / \mathrm{l} \text { mean } \pm \mathrm{SE})\end{array}$ & $\begin{array}{l}39 \cdot 8( \pm 7 \cdot 3) \\
r=0 \cdot 041\end{array}$ & $\begin{array}{l}33 \cdot 8( \pm 4 \cdot 8) \\
r=0 \cdot 201\end{array}$ & $\begin{array}{l}30 \cdot 2( \pm 5 \cdot 4) \\
\mathrm{r}=0 \cdot 058\end{array}$ \\
\hline
\end{tabular}

None of the $r$ values was statistically significant.

${ }^{*} \mathrm{p}<0.01$ compared with $\mathrm{OA}$ and control.

tp $<0.05$ compared with control.

$\ddagger \mathrm{p}<0.001$ compared with $\mathrm{OA}$ and control.

SI conversion: SUA $\mu \mathrm{mol} / 1 \times 0 \cdot 01681=\mathrm{mg} / \mathrm{l}$.

HISTOLOGY

Avascular change was found in two of the 93 femoral heads examined. Both patients were men with current alcohol consumption scores of 7 . One had a maximal lifetime score of 9 .

CHARACTERISTICS OF HEAVIEST AND LIGHTEST DRINKERS (TABLE 5)

SUA, MCV, GGT, and age were compared in the heaviest (score men 7-9, women 5-9) and lightest (score men 1-3, women 1 and 2) drinkers within diagnostic groups. Age differences in the male OA group were most significant. At current consumption levels the heaviest drinkers tended to be much younger than the lightest $(\mathrm{p}<0.01, t$ test $)$. For maximal lifetime consumption scores the differences were even more significant $(p<0 \cdot 001)$. These differences were not found in OA women or in RA or control men or women. Only in RA women were there significant differences in MCV (at current alcohol score) and GGT (at maximal lifetime score) between heaviest and lightest drinkers. In contradiction with expected results, GGT levels were higher in the lightest-drinking RA women than in the heaviest.
EFFECT OF ARTHRITIS ON PLACE OF ALCOHOL CONSUMPTION

Twelve RA and four OA patients admitted that their joint disease had influenced the frequency witto which they went out to consume alcohol at pubs:clubs, or other peoples homes; the difference was not significant.

CORRELATION BETWEEN ALCOHOL

CONSUMPTION SCORE, MCV, GGT, AND SUA (TABLE 6)

There was no correlation between any of these variables and alcohol consumption score. Meanos MCV was significantly lower in both male and female RA groups than in OA and control groupsu (probably due to a combination of iron deficiency and 'the anaemia of chronic disorders'). ${ }^{29}$ Mean GGT was higher in RA males than in other male groups.

\section{Discussion}

An important feature of the study is the low admitted consumption in all female diagnostic groups. This makes attempts to relate consumption 
to disease difficult, and our main conclusions therefore apply to male patients only.

It was not possible for us to study a totally unselected population because all patients submitted for surgery were, by definition, selected by virtue of fitness for operation. Arguably our results underestimate drinking among orthopaedic patients because some of the heaviest alcohol consumers may have been rendered unfit for operation or even have died as a result of alcohol abuse. We used total hip replacement as the criterion for inclusion of patients with degenerative hip disease because this operation represents a defined end-point of disease severity.

Our questionnaire attempted simply to establish alcohol consumption in the patients studied. For ethical and pragmatic reasons we deliberately avoided the use of $\mathrm{CAGE}^{30}$ or MAST ${ }^{31}$ questionnaires which are designed to detect 'problem drinking'. We felt that in our population of mostly elderly, often disabled patients these questions might well give offence, leading to an unacceptably high drop-out rate. 32 In any event 'problem drinking' and 'heavy drinking' are often not synonymous. ${ }^{34}$ This caution was justified by the extremely low questionnaire refusal rate.

Previous studies ${ }^{4} 6$ have confirmed that patients admitted for elective orthopaedic surgery tend to be among the heaviest-drinking hospital inpatients, but these studies have not distinguished between patients with different conditions requiring orthopaedic surgery. From our results no consistent pattern emerges, but it appears that male patients undergoing hip replacement surgery for primary hip degeneration admit to being heavier drinkers than do men with rheumatoid arthritis or minor orthopaedic conditions. Apart from the two cases of histologically proved avascular necrosis of the femoral head, both in self-confessed heavy drinkers, we found no evidence that heavy alcohol consumption led to hip destruction. However, histological sections of the femoral head may have missed avascular segments which could anyway have become unrecognisable in the presence of advanced degenerative change. Additionally, the relative youth of the heaviest-drinking OA men compared with the lightest drinkers suggests that heavy alcohol consumption is at least a part of a life style predisposing to hip degeneration. ${ }^{35}$

Men with rheumatoid arthritis seem from our study to regard themselves as lifelong light drinkers compared with men with severe OA hip and other orthopaedic conditions. The reasons for this are complex but may include a relative amnesia for habits in the prearthritic period due to profound life style alterations following the development of arthritis. However, a number of RA patients felt that drinking alcohol made their joint pain worse. This phenomenon was not associated in our survey with consumption of any particular alcoholic beverage. Some RA patients voiced concern about possible harmful interactions between their antiarthritic drugs and alcohol, while others felt that their arthritis precluded 'frivolous activities', such as social drinking. This phenomenon has been noted in other groups of patients with chronic diseases. ${ }^{9}$ Possibly some RA patients tended to understate their consumption because of fear of 'medical disapproval' of alcohol consumption with the drugs they were taking. Considering these factors together, it is clear from our study that significant numbers of RA men feel that 'alcohol and arthritis do not mix'.

Another striking feature of this study is the poor correlation between alcohol score and MCV, SUA, and GGT in all diagnostic groups of both sexes. There have been few studies attempting to correlate reported alcohol consumption with biochemical and haematological indices in patients not known to be alcoholic. ${ }^{36} 37$ Results have been conflicting; some studies report modest correlation between the reported alcohol consumption and GGT ${ }^{37} 38$ while in others there is apparently a better correlation. ${ }^{22} 23$ The pattern for GGT in our cases is anyway confused because of the reported elevation of this enzyme in RA patients. ${ }^{39-42}$ Similar controversy surrounds the value of $\mathrm{MCV}$ as a screening test. Some authors are impressed by a linear relationship between daily alcohol consumption and MCV;22 others emphasise the insensitivity of MCV elevation for detecting alcoholism. ${ }^{38}{ }^{43}$ The poor ability in our study of MCV, SUA, and GGT to discriminate between heaviest and lightest drinkers emphasises that these tests are no substitute for careful questioning and a clinical impression in assessing alcohol consumption. The low consumption of alcohol per head in the UK compared with most other European countries ${ }^{44}$ accounts for the weakness of these tests in detecting heavy alcohol consumption. ${ }^{45}$ GGT has been shown to have only $30 \%$ sensitivity as a detector of alcohol abuse in validation studies on known alcoholics and MCV even less; ${ }^{46}$ clearly they have not been helpful in our study of a group of patients who were not presumed alcoholic.

We thank Dr A Kalache and Dr F Arroyave of the Oxford University Department of Community Medicine and Psychiatry for help in the design of the questionnaire. Dr D Gath made useful criticisms. Dr J Bithell gave valuable advice on the presentation of the data. 


\section{References}

1 Special Committee on Alcoholism of the Royal College of Psychiatrists. Alcohol and alcoholism. London: Tavistock Publications, 1979: 94.

2 Paton A, Potter J F, Saunders J B. ABC of alcohol: nature of the problem. $\mathrm{Br}$ Med $J$ 1981; 283: 1318-9.

3 Anonymous. Alcohol: clearing the decks for actions. $\mathrm{Br} \mathrm{Med} \mathrm{J}$ 1982; 284: 1360.

4 Jarman C M B, Kellett J M. Alcoholism in the general hospital. Br Med J 1979; ii: 469-72.

5 Jariwalla A G, Adams P H, Hore B D. Alcohol and acute general medical admissions to hospital. Health Trends 1979; 11: 95-7.

6 Barrison I G, Viola L, Mumford J, Murray R M, Gordon M, Murray-Lyon I M. Detecting excessive drinking among admissions to a general hospital. Health Trends 1982; 14: 80-3.

7 Holt S, Steward I C, Dixon J M J, Elton R A, Taylor T V, Little $\mathrm{K}$. Alcohol and the emergency service patient. Br Med J 1980; 281: $638-40$.

8 Baum J D. A review of the psychological aspects of rheumatic diseases. Semin Arthritis Rheum 1982; 11: 352-61.

9 Petersson B, Trell E, Kristenson H. Alcohol abstention and premature mortality in middle-aged men. $\mathrm{Br} \mathrm{Med} J$ 1982; 285: 1457-9.

10 Brochner-Mortensen K. 100 gouty patients. Acta Med Scand 1941; 106: 81-107.

11 Gibson T, Kilbourn K, Horner I, Simmonds H A. Mechanism and treatment of hypertriglyceridaemia in gout. Ann Rheum Dis 1979; 38: $31-5$.

12 Kushner D S, Szanto P B. Fulminant polyarthritis, fever and cutaneous nodules in an alcoholic patient. JAMA 1958; 167: 1625-32.

13 Jones J P, Engleman E P. Osseous avascular necrosis associated with systemic abnormalities. Arthritis Rheum 1966; 9: 728-36.

14 Solomon L. Drug-induced arthropathy and necrosis of the femoral head. J Bone Joint Surg 1973; 55B: 246-61.

15 Malka S. Idiopathic aseptic necrosis of the head of the femur in adults. Surg Gynecol Obstet 1966; 123: 1057-65.

16 Gold E W, Cangemi P J. Incidence and pathogenesis of alcohol-induced osteonecrosis of the femoral head. Clin Orthop 1979; 143: 222-6.

17 Patterson R J, Bickel W H, Dahlin D C. Idiopathic avascular necrosis of the head of the femur-a study of 52 cases. J Bone Joint Surg 1964; 46A: 267-82.

18 Merle d'Aubigne R, Postel M, Mazabraud A, Massias P, Gueguen J. Idiopathic necrosis of the femoral head in adults. $J$ Bone Joint Surg 1965; 47B: 612-33.

19 Trueta J. Studies of the development and decay of the human frame. London: Heinemann, 1968: 335.

20 Savile P D, Dickson J. Age and weight in osteoarthritis of the hip. Arthritis Rheum 1968; 11: 635-44.

21 Pritzker K H. Which comes first: osteonecrosis or osteoarthritis? $J$ Rheumatol 1983; 10 (suppl 9): 53-4.

22 Whitehead T P, Clarke C A, Whitfield A G W. Biochemical and haematological markers of alcoholic intake. Lancet 1978; i: 978-81.

23 Whitfield J B, Hensley W J, Bryden D, Gallagher H. Some laboratory correlates of drinking habits. Ann Clin Biochem 1978; 15: 297-303

24 Ropes M W, Bennett E A, Cobb S, Jacox R, Jessar R. 1958 revision of diagnostic criteria of rheumatoid arthritis. Bull Rheum Dis 1959; 9: 178-9.

25 Wolfe S J, Summerskill W H J, Davidson C S. Thickening and contraction of the palmar fascia (Dupuytren's contracture) associated with alcoholism and hepatic cirrhosis. $N$ Engl $J$ Med 1956; 255: 559-63.

26 Edwards G, Chandler J, Hensman C. Drinking in a London Suburb. (1) Correlates of normal drinking. $Q J$ Stud Alcoho $L$ 1972; suppl 6: 69-93.

27 Sobell L C, Maisto S A, Sobell M B, Cooper A M. Reliability of alcohol abusers' self-reports of drinking behaviour. Behav Res Ther 1979; 17: 157-60.

28 Orlowski M, Meister A. $\gamma$-Glutamyl-p-nitroanilide: a new convenient substrate for determination and study of L-ands D- $\gamma$-glutamyltranspeptidase activities. Biochim Biophys Acta1965; 73: 679 .

29 Callender $\mathrm{S}$. The anaemia of chronic disorders. In Weatheral $L$ D J, Ledingham J G G, Warrell D A, eds. Oxford textbook of medicine. Oxford: Oxford University Press, 1983: 19: 15.

30 Mayfield D, McLeod G, Hall P. The CAGE questionnaire validation of a new alcoholism screening instrument. $A m$ Psychiatry 1974; 131: 1121-3.

31 Selzer M L. The Michigan alcoholism screening test: the questio for a new diagnostic instrument. Am J Psychiatry 1971; 127 $1653-8$.

32 Hurt R D, Morse R W, Swenson W M. Diagnosis of alcoholismo with a self-administered alcoholism screening test. Results with 1002 consecutive patients receiving general examinations. Mayo Clin Proc 1980; 55: 365-70.

33 Anonymous. Screening tests of alcoholism? Lancet 1980; ii 1117-8.

34 Wodak A D, Saunders J B, Ewusi-Mensah I, Davis $M \overrightarrow{0}$ Williams R. Severity of alcohol dependence in patients witloo alcoholic liver disease. $\mathrm{Br}$ Med J 1983; 287: 1420-2.

35 Cahalan D. Quantifying alcohol consumption: patterns and problems. Circulation 1981; 64(suppl 111): 7-14.

36 Kristensen H, Trell E. Indications of alcohol consumption comparisons between a questionnaire (Mm-MAST), interview and serum $\gamma$-glutamyltransferase (GGT) in a health survey of middle-aged males. Br J Addict 1982; 77: 297-304.

37 Robinson D, Monk D, Bailey A. The relationship between serum $\gamma$-glutamyltranspeptidase level and reported alcoho $\vec{B}$ consumption in healthy men. J Stud Alcohol 1979; 40: 896-9013

38 Chick J, Kreitman N, Plant M. Mean cell volume and $\gamma$-glutamyltranspeptidase as markers of drinking in workin men. Lancet 1981; i: 1249-51.

39 Dixon J S, Bird H A. Wright V. A comparison of serun biochemistry in ankylosing spondylitis, seronegative and sero을 positive rheumatoid arthritis. Ann Rheum Dis 1981; 40: 404-8음

40 Spooner R J, Smith D H, Bedford D, Beck P R. Serum?. $\gamma$-glutamyltransferase and alkaline phosphatase in rheumatoid arthritis. J Clin Pathol 1982; 35: 638-41.

41 Rau R. $\gamma$-Glutamyltranspeptidase in chronic polyarthritis. $Z$ Rheumatol 1977; 36: 49-59.

42 Lowe J R, Pickup M E, Dixon J S, et al. $\gamma_{\supset}$ glutamyltranspeptidase levels in arthritis: a correlation witio clinical and laboratory indices of disease activity. Ann Rheun Dis 1978; 37: 428-31.

43 Stimmel B, Korts D, Jackson G, Gilbert H S. Failure of mean red cell volume to serve as a biologic marker for alcoholism in narcotic dependence. Am J Med 1983; 74: 369-74.

44 Special Committee on Alcoholism of the Royal College of Psychiatrists. Alcohol and alcoholism. London: Tavistock Publications, 1979: 95.

45 Penn R, Worthington D J. Is serum $\gamma$-glutamyltransferase की misleading test? $\mathrm{Br}$ Med $J$ 1983; 286: 531-5.

46 Bernadt M W, Taylor C, Mumford J, Smith B, Murray R M: Comparison of questionnaire and laboratory tests in the detection of excessive drinking and alcoholism. Lancet 1982; i용 325-8. 